Transport and Low-carbon Fuel: A Study of Public Preferences in Spain

María L. Loureiro

Xavier Labandeira

Michael Hanemann 


\title{
Transport and Low-carbon Fuel: A Study of Public Preferences in Spain
}

\author{
Maria L. Loureiroa, ${ }^{a}$, Xavier Labandeirab,c, Michael Hanemann ${ }^{d}$ \\ a University of Santiago de Compostela, Department of Economic Theory, Avda. das Ciencias s/n, Campus Norte, 15782, Spain \\ ${ }^{b}$ Rede, Universidade de Vigo, Facultade de CC.EE., Campus As Lagoas s/n, 36310 Vigo, Spain

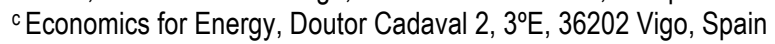 \\ d Arizona State University, Department of Economics, PO Box 879801 Tempe, AZ 85287, U.S.
}

\begin{abstract}
Transport is essential for the control of future greenhouse gas (GHG) emissions and thus a target for active policy intervention in the future. Yet, social preferences for policies are likely to play an important role. In this paper we first review the existing literature on preferences regarding lowGHG car fuels, but also covering policy instruments and strategies in this area. We then present the results of a survey of Spanish households aimed at measuring preferences for climate change policies. We find a positive WTP (in the form of higher car fuel prices) for a policy to reduce GHG emissions through biofuels. There is, however, significant heterogeneity in public preferences due to personal motivations (accounted for via factor analysis of responses to attitudinal questions) and to socio-demographic variables.
\end{abstract}

Keywords: biofuels, WTP, contingent valuation

JEL classification: Q54, Q58, R48

* Corresponding author. Phone: +34 881811674

E-mails: maria.loureiro@usc.es (Loureiro), xavier@uvigo.es (Labandeira), michael.hanemann@asu.edu (Hanemann). 


\section{Introduction}

Economic development has been historically associated with an increase in personal mobility. Industrialized countries have satisfied such a growing demand for mobility through larger transport infrastructures, public transport networks and, above all, mass private motorization. Yet, given the traditional high reliance of private transport on oil products, the so-called 'energy problems' of transport are a growing concern (Proost and Van Dender, 2012). Acute energy dependence, for instance, has prompted most oil importers to introduce various regulations (e.g. taxes, speed limits, energy efficiency standards, etc.) to deal with energy security concerns and reduce the export of rents to petroleum producing countries. Another pressing issue is local pollution (e.g. volatile organic compounds, nitrogen oxides, noise, etc.), which produces significant welfare impacts mainly through health-related morbidity and mortality effects (Krzyzanowski et al., 2005).

Transport is also a major contributor to greenhouse gas (GHG) energy-related emissions, which have been identified as a cause of climate change. Indeed, in most developed countries GHG emissions from transportation are not only quite sizable (approximately $20 \%$ of total EU emissions in 2010, as reported by the EEA, 2012), but also are growing rapidly. This is due mainly to the rising demand for personal mobility, noted above, the difficulty of switching to low-GHG technologies in this sector (when compared, for example, to switching the fuel source in electricity generation) and to the limited effectiveness of regulations. The latter is illustrated by the tendency for recent, mostly standardrelated, energy-efficiency gains in cars to be partially or completely offset by the purchase of larger and more powerful automobiles (see e.g. Knittel, 2012) and by the growth in fleet size and vehicle usage.

How to deal with the problem of energy use in transportation, and particularly with its considerable GHG emissions? Public intervention should obviously play an important role, given the externalities involved. However, many options are available: pricing (e.g. fuel taxes), design standards (e.g. minimum miles-per-gallon standards), information (e.g. energy efficiency labels), promotion of public transit, subsidies to vehicles running on renewables or non-fossil fuels, etc. Despite the existence of such policy options, many countries seem to be failing to cope with the problem, given the continuing rise in vehicle usage and transportation fuel consumption (see e.g. IEA, 2012). Apart from possible 
failures of policy design and negative interactions among policy instruments, there seem to be social constraints on introducing stronger or more restrictive policies in this area because those would be seen as an outright attack on current lifestyles (Sandmo, 2009).

This is the general context for the paper, which focuses on the role of public preferences in explaining regulatory limits in this area. We deal with just one of the 'energy problems' of transport, namely GHG emissions, and with a policy to foster the production of low-GHG fuels by current suppliers. Although we recognize other options to mitigate GHG emissions from private transport (mostly behavioral changes and replacement of high-consuming cars for more efficient conventional units or for new technological alternatives, as briefly discussed in Section 2), our main focus is on the use of biofuels since this is currently the most well developed and immediately available alternative for low-carbon transport ${ }^{1}$. Even though there has been a hot debate on the environmental and economic effects of biofuels, a new generation of biofuels seems to be tackling some of the initial and most pressing problems of this option². However, the paper is not just an empirical exercise on the Spanish WTP for biofuels as the application incorporates a wider discussion on other policy alternatives: indeed the results reported in this paper are part of a wider research program on Spanish climate change policies that focused on the promotion of low-GHG options across different sectors (Hanemann et al., 2011).

There are several factors that triggered our interest in the public preferences for low-GHG car fuels in a country like Spain. First of all, Spain is a developed country that shares most of the characteristics noted above (see European Commission, 2011): a remarkable increase in mobility and GHG transport emissions (+66\% between 2010 and 1990, which represent around $25 \%$ of total emissions nowadays) caused by both a dramatic increase in road infrastructure (around 16,000 Km of motorways in early 2012, only behind US and China in absolute terms) and in the size of the car fleet (around 0.5 cars per capita in 2009, $+50 \%$ with respect to 1991), and a limited demand response to fuel price increases (see e.g. Labandeira et al., 2006). Yet there are some significant differences as

\footnotetext{
1 Biofuels (biodiesel and bioethanol) do not require swift changes in the car fleet, as they can be used mixed (even unmixed in the case of biodiesel) with diesel and gasoline in current fuelling infrastructures. Actually, in many countries (e.g. in EU members) there are binding objectives for minimum shares of biofuels in available car fuels.

2 The first generation of biofuels relied largely on food crops. The second generation is based on the use of agricultural wastes (i.e. with no effects on food production and prices), algae and other non-food crops with high capture of atmospheric GHG concentrations and significant growth rates (see e.g. Carriquiry et al., 2011).
} 
well: a remarkably low taxation of car fuels (approximately 20\% below European averages in 2010, as depicted in Labandeira, 2011), a huge dieselization of the fleet due to lower taxes on diesel, and the corresponding intensification of local pollution problems in Madrid and Barcelona (see e.g. Monzón and Guerrero, 2004). Moreover, Spain has adopted a rather proactive approach to the current European legislation, Directive 2009/28/EC, as it has set a renewable energy target (as percentage of final energy consumption) in the transport sector 3.6 points above the $10 \%$ binding European objective for 2020 (Cansino et al., 2012). These initiatives may lead to significant future changes in the transport sector in Spain, providing a useful context for the present study.

The following section presents an overview of the literature on public preferences regarding low-GHG transport options and policies, with an emphasis on biofuels. Section 3 describes the survey implemented with a representative sample of the Spanish public and summarizes the responses. Section 4 presents an empirical strategy for estimating the willingness to pay (WTP) for biofuels of Spanish households that accounts for latent variables related to underlying motivations; this utilizes a factor analysis of the responses to attitudinal questions in the questionnaire. Section 5 presents the results of the estimation. Some concluding remarks are presented in Section 6.

\section{Literature: Preferences for cleaner private transportation}

Private transport, particularly by car, is so widespread in modern societies that policies with an impact in this area could have profound public implications. A growing strand of the academic literature on energy and transport economics has dealt with public preferences for cleaner transportation. Without presenting an exhaustive review, in this section we describe a selection of papers that have dealt with policy instruments and strategies (including mode shifts), and the specific promotion of biofuels.

With respect to social attitudes towards policy interventions, Anderson and Stradling (2004) examine the effects of doubling car fuel prices in 10 years, congestion pricing in city centers, improvements in public transport reliability and price reductions for public transit in Scotland. They find a significant heterogeneity (dependent on income, location, age, etc.) in the effects of such 'carrot and stick' policies on individual car use. Also in the UK and with a similar set of policies, Thorpe et al. (2000) 
analyze the public acceptability of generic measures to manage transport, alternative transport options, and the use of public funds obtained through taxes and charges. They show that a combination of better public transit and pricing of car use in city centers is the preferred option. Dietz et al. (2007) analyze public preferences for several GHG mitigation measures related to transport in the US indicating that a climate-related gasoline tax has little support when compared to standards on emissions per Km or taxes on high-polluting automobiles. Hersch and Viscusi (2006) use a survey of European citizens to study the support for environment-related gasoline price increases, finding a limited willingness to pay increased gasoline prices especially among older people. In a similar setting, Hsu et al. (2008) analyze the factors that influence the unpopularity of gasoline taxes in Vancouver (Canada); limited reliance on cars, residence in a 'green' constituency, income, and environmental earmarking of revenues are all factors leading to support for increased gasoline taxes.

There are many papers on public preferences towards biofuel promotion and use. Delshad et al. (2010) use surveys and focus groups to analyze attitudes towards different policies to promote biofuels in the US state of Indiana. Although most people are in favor of a public promotion of biofuels, there is a varying support for some specific policies (minimum quantity standards, subsidies to non-food crops, etc.) that seem largely related to justice concerns. Li et al. (2013) study the preferences of US consumers regarding the purchase of flexible-fuel and hybrid cars, finding again a significant heterogeneity: respondents concerned about climate change and energy security are more likely to favor these types of cars. In addition, rural residents generally favor flexible-fuel automobiles, unlike those who believe that agricultural lands should just be used for food crops and thus prefer hybrid cars. Brownstone et al. (2000) use stated and revealed preference data to study the public preferences for four types of car fuels in California (gasoline, natural gas, electricity and biomethanol), finding that natural gas and bio-methanol are generally preferred to gasoline, although people with university education favor electric cars.

A number of articles have specifically addressed consumers' WTP for biofuels used in transportation. Giraldo et al. (2010) use a survey of diesel-car drivers conducted in the city of Zaragoza to elicit perceptions and WTP for biodiesel. They show that, although drivers have a limited knowledge of this product, there is a positive perception of biodiesel due to its lower GHG emissions and other environmental impacts, with consumers willing to pay a premium for biodiesel of up to $5 \%$ over the 
price of standard diesel. Savvanidou et al. (2010) conduct a survey of car users and report a similar lack of knowledge on biofuels in Greece, even though around $45 \%$ of drivers would be willing to pay a premium for biofuels (an average WTP of 0.078 Euro/l over the standard fuel). Solomon and Johnson (2009) use contingent valuation to obtain the WTP for (non-food) biomass ethanol in three US states finding that the main factors are income levels, political orientation, gender and concern about climate change. Also in the US, Petrolia et al. (2010) use contingent valuation to analyze the preferences of consumers regarding fuels with different percentages of ethanol (E-10 and E-85). In general they observe a positive perception and WTP towards these fuels, although consumers generally favor other alternatives for transport. Finally, Zhang et al. (2011) analyze the attitudes of Chinese drivers in the area of Nanjing regarding the introduction of biofuels. As in other papers, Nanjing consumers have a limited knowledge of these fuels but generally exhibit a positive perception of their use due to the reduction in GHG emissions and energy dependence.

\section{Survey and data}

As noted above, this study is part of a wider program on public preferences regarding climate change policies in Spain that began in mid 2010 through a contingent valuation survey of a representative sample of the Spanish population (for an introductory description see Hanemann et al., 2011). Our objective was to investigate citizens' WTP for policies that could reduce GHG emissions in two sectors most responsible for those emissions in Spain, electricity and automobile transportation, with a simultaneous and comprehensive analysis of their attitudes towards climate policies and strategies. The program was intended to contribute to the growing international literature in this area (for a review, see Johnson and Nemet, 2010), providing results for a country traditionally quite active in the promotion of renewable sources of energy.

As customary in this type of applications, we followed three steps: focus groups in a selection of Spanish cities, survey pre-testing, and field implementation. The latter was carried out through faceto-face questionnaires, applying quotas by age and sex. In total, 750 completed surveys were collected using a multiple-stage method for the sampling strategy that followed the procedures of the Spanish Institute of Statistics (INE). First, different areas were selected in each Spanish region, 
including large, medium and small cities, following their frequency and representativeness at the national level. Next, interviewers were assigned to the different areas and instructed on how to collect the data.

The questionnaire contained four parts: a) introduction, where questions on climate change awareness were included; b) the valuation of electricity and transport policies aimed at reducing GHG emissions; c) attitudinal variables; and d) socio-demographic questions.

In particular, the text relating to the transport program was:

The energy we use for our cars and trucks is the second largest source of GHG emissions in Spain. Transportation, especially passenger cars and other vehicles, accounts for $25 \%$ of Spain's GHG emissions and is growing very rapidly. The Spanish government is considering a policy to require oil companies to produce gasoline and diesel that has lower GHG emissions per liter than the current gasoline and diesel. This would be phased in slowly. Most of the cost of the new investment would fall on the oil companies but there would also be some small increase in the cost of gasoline/diesel.

Respondents were asked whether they owned a car and, if so: a) which type of car (small, mediumsized, large, SUV); b) whether they usually drove to work; c) how many Km they drove in a normal week; and c) what type of fuel they used (gasoline, diesel, biofuel). The text then continued:

Currently oil companies are developing new types of fuel that produce lower GHG emissions while increasing the mileage per liter you obtain. The price of gasoline or diesel is now about 1 Euro per liter. Would you be willing to pay $X$ extra Euros per year for all the fuel you use to reduce your $G H G$ emissions when driving?

After that, respondents were asked how sure they were regarding their answer on a scale of 1 (unsure) to 10 (completely sure). They were also asked whether they would modify their car use in case of an extra cost of 10 Euros per $100 \mathrm{Km}$, and how they would do it (by car sharing, public transit, cycling or walking, etc.).

A specific question was designed for those respondents who owned a large car or a SUV. They were told that the government was considering an increase (reduction) of purchase and property taxes on 
cars with high (low) GHG emissions ${ }^{3}$, and were asked the total cost of their automobile per year. They were then confronted with a $20 \%$ increase in annual costs and were asked whether they would opt for a low-GHG emitting vehicle in future purchases.

In terms of comparability of the sample with the general census and other INE data (household expenditure survey, household environmental survey), the sample reflects quite well the Spanish population 4 . About $48 \%$ of respondents are males (49\% in the census); $34 \%$ are aged $35-54$ (37\% in the census), and $40 \%$ are on salaries ( $44 \%$ in the census). The regional distribution of respondents approximately follows that in the census (e.g. $20 \%$ in Andalusia versus $18 \%$ in the census; $12 \%$ in Madrid versus $9 \%$ in the census; $13 \%$ in Catalonia versus $11 \%$ in the census, and similarly for all 17 regions). The education levels reported in the sample also match the census: $35 \%$ of the sample has completed primary school, $40 \%$ secondary school, and around 20\% has a university degree. Moreover, the transportation information reported by the sample matches INE data: $78 \%$ of citizens report having a car ( $77 \%$ in INE data), with a similar distribution of the fleet (31\% of small cars, $28 \%$ following INE; $43 \%$ mid-sized cars, $43 \%$ in INE, etc.) and choice of fuel (diesel $48 \%, 51 \%$ in INE; gasoline 43\%, 45\% following INE).

In other results, respondents state they often drive to work (56\%), and drive less than $400 \mathrm{Km}$ per week (71\%). Even with a 10 Euro extra cost per $100 \mathrm{Km}$, they would mostly retain their level of car use (45\% vs. $41 \%$ who would change their driving habits). Those who change their car use would mostly switch to public transit $(25 \%)$ and car sharing (15\%). This reflects a low price elasticity of demand for private car use, which is consistent with the general finding in the literature. Drivers of large-cars and SUVs also show a limited reaction to increased taxes on their automobiles, as only one third of them would be incentivized to purchase a low-GHG car in the next occasion.

Table 1 describes the stated responsibility towards the climate change process in Spain. Participants are clearly aware of climate change and consider it a real phenomenon (77\%), while the overwhelming majority believes that it will be harmful (91\%). They also feel that measures are

\footnotetext{
${ }^{3}$ Actually, a car purchase tax levied on $\mathrm{CO}_{2}$ emissions per $\mathrm{Km}$ was introduced in Spain in 2008. At the moment of writing, the Spanish government is contemplating an emission-related fiscal discrimination in the annual (local) tax on car property.

${ }^{4}$ More information on the sample is available in Section 5 (Table 5).
} 
necessary to control GHG emissions (88\%), that Spanish households (69\%) and especially firms $(95 \%)$ bear responsibility for reducing emissions, and that the Spanish government should take action now (62\%). Table 2 presents information on the attitudes of citizens towards several aspects of climate policy design. Respondents agree that households with larger energy consumption should pay more for energy (64\%), although they consider that taxes on gasoline are already too high in Spain (81\%). Opinion is split on taxes: $31 \%$ are willing to pay a tax to prevent climate change, but $42 \%$ are not willing. Around $78 \%$ believe that if environmental taxes are introduced other taxes should be reduced, that is, a large majority supports green tax reforms. $61 \%$ agree that energyefficient housing should be required, but $57 \%$ indicate that solar panels should not be promoted in natural areas. Furthermore, $38 \%$ agree that nuclear energy is a valid way to fight against climate change (although this is a pre-Fukushima survey), with 17\% disagreeing with the statement and $43 \%$ neither agreeing nor disagreeing.

As indicated before, one of the advantages of the survey is the in-depth treatment of attitudes towards climate policies and strategies. Indeed, the large number of attitudinal questions provides an opportunity to understand the latent hidden preferences behind the actual responses given to each specific question by each individual. Furthermore, severe multicollinearity problems may arise due to the high correlation of these attitudinal variables. Therefore, in the following section we employ factor analysis to reduce the number of attitudinal variables without giving up information about the latent constructs that may explain public preferences regarding low-GHG policies in Spain. 
Table 1. Stated responsibility towards climate change in Spain

\begin{tabular}{|c|c|}
\hline $\begin{array}{l}\text { Extent to which Spanish households should assume responsibility in reducing atmospheric } \\
\text { pollution } \\
\text { No responsibility } \\
\text { Small responsibility } \\
\text { Large responsibility } \\
\text { Total responsibility } \\
\text { DK/NA }\end{array}$ & $\begin{array}{r}5.2 \% \\
25.3 \% \\
51.5 \% \\
17.7 \% \\
0.3 \%\end{array}$ \\
\hline $\begin{array}{l}\text { Extent to which firms should be responsible for reducing atmospheric pollution } \\
\text { No responsibility } \\
\text { Small responsibility } \\
\text { Large responsibility } \\
\text { Total responsibility } \\
\text { DK/NA }\end{array}$ & $\begin{array}{r}1.3 \% \\
3.0 \% \\
32.5 \% \\
62.2 \% \\
1.0 \%\end{array}$ \\
\hline $\begin{array}{l}\text { Likelihood of finding technological solutions to avoid the negative effects of climate change } \\
\text { Very likely } \\
\text { Quite likely } \\
\text { Neither likely nor unlikely } \\
\text { Little likely } \\
\text { Very little/hardly likely } \\
\text { DK/NA }\end{array}$ & $\begin{array}{r}18.9 \% \\
44.8 \% \\
14.0 \% \\
14.7 \% \\
7.4 \% \\
0.1 \%\end{array}$ \\
\hline $\begin{array}{l}\text { How necessary are measures nowadays to control GHG emissions } \\
\text { Absolutely necessary } \\
\text { Quite necessary } \\
\text { Little necessary } \\
\text { Not necessary } \\
\text { DK/NA }\end{array}$ & $\begin{array}{r}41.8 \% \\
46.8 \% \\
7.4 \% \\
2.2 \% \\
1.9 \%\end{array}$ \\
\hline $\begin{array}{l}\text { The Spanish government should do something to control GHG emissions } \\
\text { Only if developing countries cooperate and control their emissions } \\
\text { Regardless of whether or not developing countries cooperate } \\
\text { No, Spain should do nothing } \\
\text { DK/NA }\end{array}$ & $\begin{array}{r}29.0 \% \\
62.1 \% \\
4.3 \% \\
4.6 \%\end{array}$ \\
\hline
\end{tabular}

Source: the authors 
Table 2. Attitudes and preferences towards climate change in Spain

\begin{tabular}{|c|c|c|c|c|c|c|}
\hline & $\begin{array}{l}\text { Totally } \\
\text { Agree }\end{array}$ & $\begin{array}{l}\text { Quite } \\
\text { Agree }\end{array}$ & $\begin{array}{l}\text { Neither agree } \\
\text { nor disagree }\end{array}$ & $\begin{array}{l}\text { Quite } \\
\text { disagree }\end{array}$ & $\begin{array}{l}\text { Totally } \\
\text { disagree }\end{array}$ & DK/ NS \\
\hline $\begin{array}{l}\text { A.6. It is better to spend on } \\
\text { reducing emissions in developing } \\
\text { countries }\end{array}$ & $10.9 \%$ & $23.0 \%$ & $25.8 \%$ & $17.2 \%$ & $14.2 \%$ & $9.0 \%$ \\
\hline $\begin{array}{l}\text { A.7. The government should not tell } \\
\text { companies what to produce }\end{array}$ & $13.9 \%$ & $21.8 \%$ & $22.0 \%$ & $17.6 \%$ & $17.9 \%$ & $6.9 \%$ \\
\hline $\begin{array}{l}\text { A.8. The best we can do to help } \\
\text { developing countries fight climate } \\
\text { change is to help them grow }\end{array}$ & $25.5 \%$ & $39.3 \%$ & $17.3 \%$ & $8.4 \%$ & $5.9 \%$ & $3.6 \%$ \\
\hline $\begin{array}{l}\text { A.9. Funds for economic recovery } \\
\text { should be used to improve energy } \\
\text { efficiency in buildings }\end{array}$ & $15.2 \%$ & $30.5 \%$ & $28.2 \%$ & $12.9 \%$ & $10.0 \%$ & $3.1 \%$ \\
\hline $\begin{array}{l}\text { A.10. Households with greater } \\
\text { energy consumption should pay } \\
\text { more for energy }\end{array}$ & $32.2 \%$ & $31.6 \%$ & $16.5 \%$ & $8.7 \%$ & $10.0 \%$ & $1.0 \%$ \\
\hline $\begin{array}{l}\text { A.11. Taxes on gasoline are already } \\
\text { too high }\end{array}$ & $53.5 \%$ & $28.0 \%$ & $10.0 \%$ & $3.4 \%$ & $1.4 \%$ & $3.6 \%$ \\
\hline $\begin{array}{l}\text { A.12. Energy efficient housing } \\
\text { should be required }\end{array}$ & $29.2 \%$ & $31.8 \%$ & $14.9 \%$ & $14.9 \%$ & $7.2 \%$ & $2.2 \%$ \\
\hline $\begin{array}{l}\text { A.13. Nuclear energy is valid way to } \\
\text { fight climate change }\end{array}$ & $17.0 \%$ & $21.2 \%$ & $43.2 \%$ & $5.9 \%$ & $9.7 \%$ & $3.0 \%$ \\
\hline $\begin{array}{l}\text { A.14. Solar panels should not be } \\
\text { promoted in natural areas }\end{array}$ & $26.5 \%$ & $30.5 \%$ & $19.7 \%$ & $9.3 \%$ & $8.2 \%$ & $5.9 \%$ \\
\hline $\begin{array}{l}\text { A.15. Education is the best way to } \\
\text { fight climate change }\end{array}$ & $52.5 \%$ & $33.1 \%$ & $7.2 \%$ & $3.3 \%$ & $3.2 \%$ & $0.9 \%$ \\
\hline $\begin{array}{l}\text { A.16. Resources should be } \\
\text { allocated to other environmental } \\
\text { problems }\end{array}$ & $18.5 \%$ & $31.9 \%$ & $31.3 \%$ & $7.4 \%$ & $5.6 \%$ & $5.3 \%$ \\
\hline $\begin{array}{l}\text { A.18. If environmental taxes are } \\
\text { introduced, other taxes should be } \\
\text { reduced }\end{array}$ & $40.9 \%$ & $36.8 \%$ & $14.0 \%$ & $3.4 \%$ & $2.7 \%$ & $2.2 \%$ \\
\hline $\begin{array}{l}\text { A.17. Willingness to pay a tax } \\
\text { against climate change }\end{array}$ & $6.01 \%$ & $25.5 \%$ & $22.3 \%$ & $14.3 \%$ & $28.6 \%$ & $3.3 \%$ \\
\hline
\end{tabular}

Source: the authors 


\section{Empirical approach: Accounting for latent variables in the WTP function}

\subsection{An application of factor analysis}

In the empirical application that follows we employ factor analysis to reduce a set of behavioral and attitudinal survey responses (see Table 3 in Section 5) down to a small number of latent explanatory factors that affect preferences towards biofuels. Factor analysis is frequently used in social science to reduce the number of explanatory variables to few relevant factors that describe the motivational structure of respondents (see Harman, 1976). The assumption is that there exist a number of unobservable latent variables (or factors) that account for the correlations among the observed variables such that, if the latent variables are partialled out or held constant, the partial correlations among observed variables all become zero. Thus, these latent factors determine the observed variables, which in our particular case study are the responses to the attitudinal questions displayed in Table 1 and Table 2. Thus, each observed variable, can be expressed as a weighted composite of a set of latent variables $\left(f^{\prime} s\right)$ such that

$$
Y_{i}=a_{i 1} f_{1}+a_{i 2} f_{2}+\cdots+a_{i k} f_{k}+e_{i}
$$

where $Y_{i}$ is the $i^{\text {th }}$ observed variable on the factors, and $e_{i}$ is the residual term. Based on the assumption that residuals are uncorrelated across the observed variables, the correlations among the observed variables are accounted for by the factors.

The empirical results from this factor analysis will allow us to incorporate latent constructs into the WTP analysis for green fuels, using the derived factors as explanatory variables in the empirical model of Section 4.2. This empirical application involves three steps in the modeling of factor analysis. First we extract the initial motivational factors underlying the responses by employing the eigenvalue rule to select the optimal number of factors and to perform the confirmatory analysis of the factors. Next, we estimate the various motivational factors. Finally, the estimated factors are included into the WTP analysis as explanatory variables. The results of this process are presented in Section 5. 


\subsection{Modeling WTP for private transport policies in Spain}

Preferences for transportation policies largely depend on the use of private vehicles and the availability of alternative public transport. Given that this paper uses a sample of representative households to produce an empirical study of public preferences for low-GHG car fuels in Spain, it must necessarily address selection bias. Selection bias emerges in our sample due to the fact that not all households own a car and, as such, preferences for biofuels are highly conditioned on their driving practices.

Keeping this in mind, our modeling strategy is based on a bivariate probit with selection that incorporates in the probit WTP equation the principal factors previously extracted and selected based on our confirmatory analysis. A similar way of integrating latent variables into a WTP framework has been conducted by Nunes (2002), who used a very extensive attitudinal questionnaire in order to uncover preferences for protection of natural areas in Portugal.

The probit model with sample selection assumes that there exists an underlying relationship, such that

$$
W T P_{j}^{*}=x_{j} \beta+u_{1 j}
$$

where $W T P_{j}^{*}$ is the individual's non-observable WTP for the low-GHG fuels, being a function of the explanatory variables contained in $x_{j}$.

We only observe the bivariate outcome or response to the dichotomous question, such that

$$
W T P_{j}=\left(W T P_{j}^{*}>0\right)
$$

The dependent variable, however, is not always observable. Rather, the dependent variable for observation $j$ is observed if 


$$
\text { Drive }_{j}=\left(z_{j} \gamma+u_{2 j}>0\right)
$$

that is, when the participant drives regularly. Driving is modeled as a function of the explanatory variables $z_{j}$, where $u_{1} \sim N(0,1)$ and $u_{2} \sim N(0,1)$, and $\operatorname{corr}\left(u_{1}, u_{2}\right)=\rho$. Furthermore, if $\rho \neq 0$, the application of the standard probit will yield biased results.

\section{Results}

\subsection{Factor analysis}

The estimation used Stata 11.0 and the results from the factor analysis extraction are displayed in Table 3. In this first exploratory step, no prior limit was imposed on the number of factors. Instead, the Kaiser test (Kaiser, 1960) was used to determine the relevant number of factors. The logic behind the Kaiser rule is that each observed variable contributes one unit of the variance of the total variance in the dataset. Thus, any component that displays an eigenvalue greater than one accounts for a greater amount of the variance than had been contributed by one single variable. A component that carries an eigenvalue less than one, accounts for less variance than that contributed by just one single variable. The results presented in Table 3 suggest the retention of just two factors that carry an eigenvalue greater than one. Table 4 presents the rotated factor loadings that show the relative contribution of each of the attitudinal variables to the retained factors. The two factors that will be used as explanatory variables in the WTP probit model (see Table 5) are:

- Factor 1 is associated with attitudinal variables related to the 'need for action now' and that 'education' is the best way to tackle climate change problems (see Table 1 and Table 2). That is, it aggregates concerns about climate change with pro-social responses, but not with economic commitment. We denote this factor as 'social desirability bias'.

- Factor 2 is associated with attitudinal variables reported in Table 2 that are more related to economic concerns ('willingness to pay higher taxes') but also government trust ('the 
government knows less than the market'), and the existence of other mitigation options that may be cheaper ('domestic firms should reduce emissions abroad'). We denote this factor as 'economic-based concerns'.

Table 5 contains the descriptive statistics for the variables used in the estimation of the selection model (see Section 3 for further details on the data). The variables considered in the econometric analysis include determinants of the demand for driving and WTP, although only the observations without missing values were retained. The role of household income is particularly relevant, with $14.5 \%$ of the respondents having an annual gross income under 10,800 Euros; $59.7 \%$ between 10,800 and 21,600 Euros; and 25.6\% over 21,600 Euros. In order to account for the potential nonlinear effects associated with income, this variable is also included in its squared form (income2). The bid amount (the price increase presented to the respondent) ranges from 25 to 400 Euros per year and was assigned at random to respondents.

Table 3. Factor analysis-extraction of factors

\begin{tabular}{lllll}
\hline Factor & Eigenvalue & Difference & Proportion & Cumulative \\
\hline Factor1 & 1.79101 & 0.75315 & 0.6460 & 0.6460 \\
Factor2 & 1.03786 & 0.58640 & 0.3743 & 10.203 \\
Factor3 & 0.45146 & 0.03607 & 0.1628 & 11.832 \\
Factor4 & 0.41539 & 0.19217 & 0.1498 & 13.330 \\
Factor5 & 0.22322 & 0.08393 & 0.0805 & 14.135 \\
Factor6 & 0.13929 & 0.01644 & 0.0502 & 14.638 \\
Factor7 & 0.12286 & 0.04246 & 0.0443 & 15.081 \\
Factor8 & 0.08040 & 0.08560 & 0.0290 & 15.371 \\
Factor9 & -0.00520 & 0.03904 & -0.0019 & 15.352 \\
Factor10 & -0.04424 & 0.06991 & -0.0160 & 15.193 \\
Factor11 & -0.11415 & 0.01477 & -0.0412 & 14.781 \\
Factor12 & -0.12892 & 0.06167 & -0.0465 & 14.316 \\
Factor13 & -0.19060 & 0.01124 & -0.0687 & 13.628 \\
Factor14 & -0.20184 & 0.04208 & -0.0728 & 12.900 \\
Factor15 & -0.24392 & 0.01824 & -0.0880 & 12.020 \\
Factor16 & -0.26217 & 0.03583 & -0.0946 & 11.075 \\
Factor17 & -0.29800 &. & -0.1075 & 10.000 \\
\hline
\end{tabular}

Source: the authors 
Table 4. Rotated factors

\begin{tabular}{|c|c|c|c|}
\hline & Factor1 & Factor2 & Uniqueness \\
\hline 1. Firms-responsibility & -0.4038 & 0.2851 & 0.7556 \\
\hline 2. Own-responsibility & -0.2861 & 0.3932 & 0.7635 \\
\hline 3. Science-finds-solution & 0.1960 & -0.0626 & 0.9577 \\
\hline 4. Need-for-action-now & $0.5895^{*}$ & -0.0255 & 0.6518 \\
\hline 5. Spain-should-do-something & 0.2821 & 0.2011 & 0.8800 \\
\hline 6. Emissions-outside & 0.0251 & $0.4160^{*}$ & 0.8263 \\
\hline 7. Government-knows-less & 0.0632 & $0.4746^{*}$ & 0.7708 \\
\hline 8. Economic-growth & -0.2092 & 0.2996 & 0.8664 \\
\hline 9. Efficient-buildings & -0.0890 & 0.3312 & 0.8824 \\
\hline 10. High-consumption-high-pay & 0.4129 & -0.0907 & 0.8213 \\
\hline 11. Taxes-too-high-already & 0.2349 & 0.1350 & 0.9266 \\
\hline 12. Nuclear-alternative-solution & -0.2518 & -0.1737 & 0.9064 \\
\hline 13. Natural-areas-protection & -0.2865 & 0.0227 & 0.9174 \\
\hline 14. Education-best-policy & $0.5124^{*}$ & -0.1551 & 0.7134 \\
\hline 15. Many-other-problems & -0.0357 & -0.1860 & 0.9641 \\
\hline 16. WTP-environmental-taxes & -0.2421 & $0.4760^{*}$ & 0.7149 \\
\hline 17. New-revenue-neutral-taxes & 0.3323 & 0.1925 & 0.8525 \\
\hline
\end{tabular}

Table 5. Socio-demographic descriptive statistics

\begin{tabular}{lcc}
\hline Description & Mean & Std.Dev. \\
\hline WTPdrive & 0.3229 & 0.4680 \\
Infoclimate & 2.606061 & 0.7365 \\
Bid & 153.4335 & 123.6344 \\
Age & 45.9442 & 15.9213 \\
Income & 5.0917 & 1.5310 \\
Income2 & 28.3754 & 14.7978 \\
& & \\
Woman & 0.5178 & 0.5000 \\
Salary & 0.4392 & 0.4966 \\
Buses & 3.6039 & 3.5784 \\
Self-employed & 0.0972 & 0.2965 \\
& & \\
\hline
\end{tabular}

Source: the authors 
Regarding other socio-economic characteristics that may affect demand, $51.8 \%$ of participants are women with an average age of about 46 years. Participation in labor markets (a pooling factor for mobility) is represented through the inclusion of the variable salary, which denotes the percentage of participants who earn a salary (43.9\%) versus other sources of income such as pensions, unemployment benefits, etc. Of special interest is the category of self-employed individuals, who tend to drive more than the average ( $9.7 \%$ of the sample). To assess the impact of the availability of potential substitute means of transportation, our survey data were augmented with data for each province from INE. In particular, we gathered the number of registered buses (in thousands) in the province, which are included as a proxy variable for public transit. In order to capture the knowledge about climate change, the variable infoclimate has been included, which reflects how informed participants feel about global climate change, taking values on a scale from 0 (not informed at all) to 3 (very well informed), with a mean of 2.6. In addition, the two factors described above were also included to control for attitudes, where factor 1 denotes a 'social desirability' effect, and factor 2 is linked to other 'economic-based considerations'. The dependent variable of the selection equation is the indicator drive, which shows that about $57 \%$ of participants in the sample usually drive to work. From those, about $32 \%$ are willing to pay a higher price for low-GHG fuels.

Table 6 presents results of the bivariate probit model. The results are as expected, and the bivariate probit modeling specification turns out to be statistically significant according to the critical value of the $\rho$ coefficient, as displayed at the bottom of Table 6 . This implies that modeling the WTP equation independently of the selection equation would provide biased coefficient estimates because of sample selection. In this table, the WTP equation is presented in the upper part, while the results on the selection equation (drive) are presented at the bottom. The selection equation is a probit model assessing whether the participant has a car and drives regularly to work. This decision is modeled as a function of job market participation, type of job, gender, age and whether public transport is available (reflected in the INE census as the number of buses in the area of residence).

In terms of market participation, we find that participants with a job, and particularly self-employed professionals, are more likely to drive than other respondents. These results provide clear evidence of the importance of commuting to work in private transportation decisions. Furthermore, females are less likely to drive than males. This may be due to the lower labor market participation of females, or 
to their selection of jobs near to the household in order to better meet family and work obligations. Furthermore, as expected, the public supply of other transit services decreases the usage of automobiles for daily transportation. In general all the preceding results follow intuition, are similar to those reported in the literature 5 .

Table 6. Bivariate probit with sample selection: WTP for low-GHG fuels

\begin{tabular}{|c|c|c|c|c|}
\hline & Coefficient & Std. Err. & Z & $\mathrm{P}>|\mathrm{z}|$ \\
\hline \multicolumn{5}{|l|}{ WTPdrive } \\
\hline Bid & -0.0021 & 0.0007 & -3.06 & 0.002 \\
\hline Infoclimate & 1.8849 & 0.1055 & 1.79 & 0.074 \\
\hline Factor1='Social-desirability' & 0.2761 & 0.0964 & 2.86 & 0.004 \\
\hline Factor2='Economic Concerns' & -0.1688 & 0.1013 & -1.67 & 0.096 \\
\hline Age & 0.0105 & 0.0051 & 2.06 & 0.040 \\
\hline Income & -0.8254 & 0.2869 & -2.88 & 0.004 \\
\hline Income2 & 0.0857 & 0.0293 & 2.93 & 0.003 \\
\hline Woman & 0.5090 & 0.1581 & 3.22 & 0.001 \\
\hline Constant & 1.1583 & 0.6560 & 1.77 & 0.077 \\
\hline \multicolumn{5}{|l|}{$\begin{array}{c}\text { SELECTION } \\
\text { equation= drive }\end{array}$} \\
\hline Salary & 0.5143 & 0.1221 & 4.21 & 0.000 \\
\hline Woman & -0.5562 & 0.1132 & -4.91 & 0.000 \\
\hline Buses & -0.0663 & 0.014 & -4.69 & 0.000 \\
\hline Self-employed & 0.6702 & 0.2225 & 3.01 & 0.003 \\
\hline Age & -0.0079 & 0.0034 & -2.30 & 0.021 \\
\hline Constant & 0.5336 & 0.2023 & 2.64 & 0.008 \\
\hline Rho & -0.8814 & 0.1166 & & \\
\hline $\mathrm{N}$ & 539 & & & \\
\hline
\end{tabular}

LR test $\chi_{1}^{2}=8.53$, pvalue $=0.003$

rho=0,

Source: the authors

The response to the WTP question in the survey (see Section 3), conditional upon driving, is modeled as a function of the bid amount, the socioeconomic and informational variables described above, and the two attitudinal factors (factor1=social desirability bias; factor2=economic-based concerns).As

\footnotetext{
5 However, we are not able to control for price because we use a cross-sectional dataset in which prices do not vary in practice across regions.
} 
expected, economic variables (such as the bid amount) and the income levels are statistically significant in determining WTP for low-GHG fuels. We find a negative coefficient on the bid amount (the price coefficient). Regarding the role of information about climate change, we find that there is a positive relationship between the level of information about climate change and the likelihood of paying for low-GHG fuels, being statistically significant at the 0.1 level. In addition, we find that the factor representing the pro-social responsible responses is positive and highly significant. This may be related to the existence of some sort of social desirability bias in the responses given in the questionnaire, as denoted by Nunes (2002). The factor accounting for economic concerns carries a negative sign and is also statistically significant. This result is expected as this variable contains information from questions directly linked to economic measures and attitudes towards economic instruments.

Regarding other socio-demographic variables, we find that women and older male participants are more likely to be willing to pay for low-GHG fuels, a finding reported elsewhere in the literature (see Section 2). In the case of income, we find a quadratic relationship with respect to the WTP for lowGHG fuels. In particular, the estimated WTP function with respect to income is $-0.8253+0.0857$ income $^{2}$. Taking the partial derivative of this function with respect to income, we

obtain $\frac{\partial W T P}{\text { dincome }}=-0.8253+2(0.0857)$ income . Setting this expression equal to zero, we find that there is an inflexion point when the income indicator is 4.81 (slightly below the mean, corresponding to an income between 14,400 and 18,000 Euros), which means that income levels above (below) this threshold have a positive (negative) effect on the WTP for low-GHG fuels. This is also an intuitive result, as household with low incomes (possibly unemployed or with part-time jobs) face clear budget limits and may not be willing to pay an extra amount for biofuels.

\subsection{Conditional WTP estimation}

Conditional WTP has been computed as the ratio of the grand constant term (summing all non-price explanatory variables evaluated at their respective means multiplied by the corresponding coefficient) divided by the bid coefficient. The conditional mean WTP for the above specification was computed 
as 144 Euros per year. This estimate is quite similar to the non-parametric Kapler-Meier estimate presented in Table 7. In particular, this non-parametric approach yields an estimate of about 115.5 Euros per household over total annual fuel consumption. On average, each participant in the sample drove around $400 \mathrm{Km}$ per week, roughly equivalent to $21,000 \mathrm{Km}$ per year. Our estimate shows that respondents are willing to pay an average 5.52 Euros per $1000 \mathrm{Km}$, above the price of diesel or gasoline (which at the time of the survey was roughly 1 Euro per liter 6 ), for low-GHG fuels.

Taking into account the average consumption of gasoline and diesel-fuelled Spanish cars per Km in 2010, as reported by IDAE (2010), the WTP estimate can be expressed in Euros per liter: an extra 0.07 Euro/l for biofuels in gasoline-driven cars and 0.08 Euro/l for biodiesel. These figures are consistent with findings in the literature reviewed in Section 2: for instance in the case of biodiesel our result is slightly above the estimate reported by Giraldo et al. (2010) for Spain (0.05 Euros/l) and Jeanty et al. (2007) for the US (0.03-0.05 Euros/l), but quite close to the figure reported by Savvanidou et al. (2010) for Greece.

Table 7. Estimate of the annual WTP using the Kaplan-Meier estimator

\begin{tabular}{|c|c|c|c|c|c|}
\hline $\begin{array}{l}\text { Bid } \\
\left(t_{j}\right)\end{array}$ & Yes & No & $\begin{array}{l}\text { Cdf } \\
\left(F_{j}\right)\end{array}$ & $\begin{array}{l}\text { Pdf } \\
\left(p_{j}\right)\end{array}$ & $t_{j}^{*} p_{j}$ \\
\hline 25 & 39 & 29 & 0.4265 & 0.4265 & 0 \\
\hline 50 & 36 & 30 & 0.4545 & 0.0281 & 0.7019 \\
\hline 75 & 27 & 42 & 0.5923 & 0.1378 & 6.8881 \\
\hline 100 & 26 & 35 & Pooled & & \\
\hline 175 & 20 & 45 & 0.6923 & 0.1000 & 10 \\
\hline 250 & 13 & 56 & 0.8042 & 0.1119 & 19.5804 \\
\hline \multirow[t]{4}{*}{400} & 15 & 59 & Pooled & & \\
\hline & & & 1 & 0.1958 & 78.3217 \\
\hline & & & & $E\{W T P\}$ & 115.4921 \\
\hline & & & idence & (103.40; & \\
\hline
\end{tabular}

Source: the authors

\footnotetext{
${ }^{6}$ The actual average price of diesel and gasoline in Spain during 2010 was slightly over this figure: 1.07 (diesel) and 1.16 (gasoline) Euro/l, following official data from CORES (2010).
} 


\section{Conclusions}

This paper focuses on the role of public preferences in the transition towards a more sustainable transport sector. Private transport, particularly road-related, is the cause of several and important 'energy problems' in advanced economies: dependence on foreign oil stocks, local pollution, and increasing GHG emissions. It is likely, therefore, that wider and stronger corrective policies will be introduced in the near future. Yet the increasing social demand for mobility, and a growing role of cars, may impose significant constraints on the successful design and implementation of transport policies. This is especially true for GHG mitigation in this sector, which may be seen as an attack on current lifestyles and on a basic tool for social organization and functioning.

We report the results of a contingent valuation application intended to explore in depth public attitudes and preferences towards climate change policies and strategies in Spain. There are several reasons for a Spanish case study on this topic: a large degree of energy dependence (one of the largest in the developed world), acute local environmental problems mostly associated with road transport, and a major increase in GHG transport emissions over the last two decades. At the same time, Spain is probably a good illustration of constrained policies in this area as it has kept an exceptionally low level of conventional car fuel taxation since the early 1990s, at least in EU terms. Simultaneously, Spain has embarked on an ambitious program to promote renewables within primary energy sources, which also applies to transport (with national objectives now well over EU binding targets for 2020).

Our study is based on a survey implemented of a representative sample of the Spanish population in 2010. The transport program within this research survey asked participants their WTP, in Euros per year, for the use of car fuels that would reduce GHG emissions. Given the wording of the program and the state of current technologies in this sector, low-GHG fuels can be equated to biofuels. Employing a factor analysis technique, we found that participants showed a pattern of responses that influenced in part by a pro-social attitudinal factor, potentially related to a social desirability bias, and a second factor linked to economic concerns related to the policy. Both of those factors were statistically significant and had the expected sign. Thus, this paper demonstrates the importance of 
public attitudes in the acceptability (and thus effectiveness) of policies designed to reduce GHG emissions from transport.

Regarding the average WTP estimate, we found that participants who drove were willing to pay an extra 115.5 Euros per year for low-carbon fuels which, given the average distance driven per year and the characteristics of Spanish cars in 2010, would be roughly equivalent to 0.07 Euro/l for biofuels in gasoline-driven cars and 0.08 Euro/l for biodiesel. This is generally in line with the results reported for Spain and elsewhere by other papers. We found that WTP is positively related to the level of information about climate change, income, gender (women) and age.

In sum, our Spanish empirical exercise shows that, from a public-preference perspective, low-GHG fuels seem to be an acceptable and thus feasible alternative for climate policies in the transport domain. Moreover, they may contribute to the necessary reduction of local pollution damages (see EPA, 2002) and of the level of energy dependence. Therefore, the paper may be useful for the design and implementation of future Spanish (and elsewhere) policies in this field. Yet a crucial question is whether the size of the reported WTP would be enough to cover the cost of developing and distributing biofuels. Comparatively higher production costs of biofuels and the physical limitations to large-scale production and mixing of biofuels probably suggest the desirability of diversified policy portfolio. Indeed, the recent Spanish suppression of the 10-year tax exemption on biofuel consumption, that was precisely designed to promote its use, is likely to increase the price of car fuels by approximately half the WTP premium reported here.

\section{Acknowledgements}

The authors are grateful to participants in the Fifth Atlantic Workshop on Energy and Environmental Economics and to two reviewers for their useful comments and suggestions on an earlier version of this paper. They are also grateful to Xiral López, Pablo Pintos and Ana Ramos for research support. Xavier Labandeira and María Loureiro are respectively thankful to the Spanish Ministry of Economy and Competitiveness research projects ECO2009-14586-C2-01 and ECO2009-14586-C2-02. The usual disclaimer applies. 


\section{References}

Anderson, S., Stradling, S., 2004. Attitudes to car use and modal shift in Scotland. Scottish Executive Social Research Findings, Edinburgh.

Brownstone, D., Bunch, D., Train, K., 2000. Joint mixed logit models of stated and revealed preferences for alternative-fuel vehicles. Transportation Research Part B, 34, 315-338.

Cansino, J.M., Pablo-Romero, M., Román, R., Yñiguez, R., 2012. Promotion of biofuel consumption in the transport sector: An EU-27 perspective. Renewable and Sustainable Energy Reviews, 16, 6013-6021.

Carriquiry, M., Du, X., Timilsina, G., 2011. Second generation biofuels: Economics and policies. Energy Policy, 39, 4222-4234.

CORES (2010) Boletín Estadístico de Hidrocarburos 2010. Corporación de Reservas Estratégicas de Productos Petrolíferos, Madrid.

Delshad, A., Raymond, L., Sawicki, V., Wegener, D., 2010. Public attitudes toward political and technological options for biofuels. Energy Policy, 38, 3414-3425.

Dietz, T., Dan, A., Shwom, R., 2007. Support for climate change policy: Social psychological and social structural influences. Rural Sociology, 72, 185-214.

EEA, 2012. Greenhouse Gas Emission Trends and Projections in Europe. Tracking Progress towards Kyoto and 2020 Targets. European Environment Agency, Copenhaguen.

EPA, 2002. A comprehensive analysis of biodiesel impacts on exhaust emissions. Technical report. U.S. Environment Protection Agency, Washington D.C.

European Commission, 2011. EU Transport in Figures. Office for Publications of the European Communities, Luxembourg.

Giraldo, L., Gracia, A., Do Amaral, E., 2010. Willingness to pay for biodiesel in Spain: A pilot study for diesel consumers. Spanish Journal of Agricultural Research, 18, 887-894.

Hanemann, M., Labandeira, X., Loureiro, M., 2011. Public preferences for climate change policies: Evidence for Spain. Working paper 2011-06, FEDEA.

Harman, H.H., 1976. Modern Factor Analysis.Chicago University Press, Chicago.

Hersch, J., Viscusi, W., 2006. The generational divide in support for environmental policies: European Evidence. Climatic Change, 77, 121-136.

Hsu, S.L., Walters, J., Purgas, A., 2008. Pollution tax heuristics: An empirical study of willingness to pay higher gasoline taxes. Energy Policy, 36, 3612-3619. 
IDAE, 2010. Informe Anual de Indicadores Energéticos. Instituto para la Diversificación y Ahorro de Energía, Madrid.

IEA, 2012. Key World Energy Statistics. International Energy Agency, Paris.

Jeanty, P., Haab, T., Hitzhusen, F., 2007. Willingness to pay for biodiesel in diesel engines: A stochastic double bounded contingent valuation survey. Paper presented at the American Agricultural Economics Association Annual Meeting, Portland, Oregon.

Johnson, E., and Nemet, G., 2010. Willingness to pay for climate policy: A review of estimates. La Follete School WP 2010-011.

Kaiser, H.F., 1960. The application of electronic computers to factor analysis. Educational and Psychological Measurement, 20, 141-151.

Knittel, C.R., 2012. Automobiles on steroids: Product attribute trade-offs and technological progress in the automobile sector. American Economic Review, 101, 3368-3399.

Krzyzanowski, M., Kuna-Dibbert, B., Schneider, J., 2005. Health Effects of Transport-related Air Pollution. World Health Organization, Copenhaguen.

Labandeira, X., 2011. Nuevos entornos para la fiscalidad energética. Información Comercial Española. Revista de Economía, 862, 57-80.

Labandeira, X., Labeaga, J.M., Rodríguez, M., 2006. An energy demand system for Spain. Energy Journal, 27, 87-112.

Li, X., Clark, C., Jensen, K., Yen, S., English, B., 2013. Consumer purchase intentions for flexible-fuel and hybrid-electric vehicles. Transport Research Part D, 18, 9-15.

Monzón, A., Guerrero, M.J., 2004. Valuation of social and health effects of transport-related air pollution in Madrid (Spain). Science of the Total Environment, 334-335, 427-434.

Nunes, P.A., 2002. Using factor analysis to identify consumer preferences for the protection of a natural area in Portugal. European Journal of Operational Research, 140, 499-516.

Petrolia, D.R., Bhattacharjee, S., Hudson, D., Herndon, C.W., 2010. Do Americans want ethanol? A comparative contingent-valuation study of willingness to pay for E-10 and E-85. Energy Economics, $32,121-128$.

Proost, S., Van Dender, K., 2012. Energy and environment challenges in the transport sector. Economics of Transportation, 1, 77-87.

Sandmo, A., 2009. The scale and scope of environmental taxation. DP 18, Department of Economics, $\mathrm{NHH}$. 
Savvanidou, E., Zervas, E., Tsagarakis, K.P., 2010. Public acceptance of biofuels. Energy Policy, 38, 3482-3488.

Solomon, B.D., Johnson, N.H., 2009. Valuing climate protection through willingness to pay for biomass ethanol. Ecological Economics, 68, 2137-2144.

Thorpe, N., Hills, P., Jaensirisak, S., 2000. Public attitudes to TDM measures: a comparative study. Transport Policy, 7, 243-257.

Zhang, Y., Yu, Y., Li, T., Zou, B., 2011. Analyzing Chinese consumers' perception for biofuels implementation: the private vehicles owner's investigation in Nanjing. Renewable and Sustainable Energy Reviews, 15, 2299-2309. 